\title{
MONITORINGUL PESTICIDELOR ÎN CORPUL ALBINELOR
}

\author{
Cebotari Valentina, Buzu Ion, Postolachi Olga \\ Institutul de Zoologie al MECC, or. Chișinău, Republica Moldova \\ E-mail: valentinaceb@yahoo.com
}

https://doi.org/10.53937/9789975315975.34

\begin{abstract}
The purpose of the research was to investigate pesticide residues in bee's body and to identify the most common and dangerous pesticides that can affect honeybees in the forest site. The bee samples have been analyzed to the residues of 11 most widely used pesticides. As a result of the research, it was established that most of the studied pesticides (72.7\%) wasn't registered in the bee samples, collected from the apiary, stationed in the forest site. In $20 \%$ of the analyzed bee samples no residues of either of the 11 investigated pesticides were found, in $40 \%$ of the bee samples, detectable level of residues of a single pesticide (the pyrethroidic insecticide Tau-fluvalinate) was recorded, in other $20 \%$ of the samples detectable residues of 2 pesticides (the neonicotinoid insecticide Imidacloprid and acaricide Amitraz) was recorded, and in the other $20 \%$ of the bees samples detectable residues of 3 pesticides (pyrethroid insecticide Tau-fluvalinate, insecticide neonicotinoid Imidacloprid and acaricide Amitraz) was registered. The values of detectable concentrations of pesticide residues recorded in bee samples taken from the forest site were very small, constituting on average: the pyrethroid insecticide Tau-fluvalinate - $0.0062 \pm 0.0007 \mathrm{mg} / \mathrm{kg}$; the neonicotinoid insecticide Imidacloprid - $0.0060 \pm 0.0006 \mathrm{mg} / \mathrm{kg}$ and the acaricide Amitraz - 0.0058 $\pm 0,0006 \mathrm{mg} / \mathrm{kg}$. The detected concentrations of pesticide residues are 1.7 - 32.2 times lower than the maximum admisibile limits, according to national and EU standards. Hence, the forest site environment is not polluted with pesticide residues and, therefore, doesn't represent any risk of contamination for bee families, which could compromise the bee's health and the safety of apiculture products, intended for human consumption.
\end{abstract}

Key words: monitoring, pesticides, bee body, forest site.

\section{INTRODUCERE}

Problema prezenței reziduurilor de pesticide în mediul ambiant, în contextul protecției sănătății familiilor de albine și asigurării securității alimentare umane, îngrijorează tot mai mult atât comunitatea științifică în domeniu [1, 3-6, 14], cât și specialiștii apicultori din sectorul de producție [18]. Impactul dăunător al pesticidelor se extinde nu doar asupra albinei melifere, ci și asupra altor specii importante de polenizatori [17]. Îngrijo- 
rarea din ultimul timp pe plan mondial este provoacă, în special, de pesticidele sistemice, care sunt utilizate în agricultură la tratarea semințelor și stropirea unor culturi agricole pentru combaterea insectelor dăunătoare și a buruienelor. Potrivit informației „Beyond Pesticides” (organizație științifică internațională din SUA), pesticidele neonicotinoide au efecte dăunătoare neurotoxice, de reproducere și mutagene la insecte, păsări, pești, melcii din apă dulce, râme din sol, libelule, țânțari, precum și vertebrate, menționând că "neonicotinoidele ar putea reprezenta noul dezastru ecologic contemporan, fiind o amenințare pentru natură" [7].

Organizația Mondială a Sănătății (OMS) și Agenția Internațională de Cercetare a Carcinogenelor (AICC) au anunțat, în martie 2015, că unele erbicide (Glifosatul) sunt carcinogene cu impact dăunător asupa sistemului endocrin [8]. Reziduuri ale acestor erbicide pot fi găsite în urina și sîngele animalelor, precum și a omului [9].

Potrivit altor surse de informații [10], insecticidul organoclorurat Fipronil este unul dintre principalii factori chimici care răspândesc tulburările de colaps al coloniilor de albine. Un raport din 2013 al EFSA (Autoritatea Europeană pentru Siguranța Alimentară) a identificat Fipronilul folosit pentru tratamentul semințelor ca un risc acut pentru albine, de aceea, la propunerea acestei autorități, Uniunea Europeană a votat la 16 iulie 2013 interzicerea acestui pesticid la tratarea semințelor de porumb și floarea-soarelui.

Mai mulți cercetători au demonstrat că există un sinergism de acțiune aditivă atunci când pesticidele sunt aplicate în combinație. Unele cercetări au demonstrat că un neonicotinoid comun, Tiacloprid, devine mai toxic cu aproximativ de două ori pentru albinele melifere atunci când este folosit în combinație cu fungicidul Propiconazol, și de trei ori mai toxic în combinație cu Trifumizol [11].

În alte cercetări a fost arătat că există o sinergie semnificativă între fungicide, insecticidele neonicotinoide și piretroide, precum și, acaricidele Flumetrin, Cumafos și Fluvalinat [16].

Alături de interacțiunile dintre diferite pesticide, insecticidele manifestă, de asemenea, o interacțiune și cu alți factori de stres, cum ar fi infestări cu paraziți. Spre exemplu, mortalitatea albinelor melifere a fost mai mare 
la cele infestate cu parazitul Nozema și s-a descoperit o interacțiune sinergetică între cei doi factori, ce reduce activitatea enzimatică legată de sterilizarea hranei coloniei [1].

Considerăm că florile melifere reprezintă principala verigă de răspândire în natură a pesticidelor în lanțul trofic al albinelor melifere. Fără diminuarea importanței aerului, apei și solului, florile melifere ocupă segmentul dominant în ecologia produselor apicole, deoarece din acestea se culege nectarul și polenul, ca principali predecesori ai produselor apicole. Din florile melifere, prin intermediul nectarului, trecând prin corpul albinei (cavitatea bucală și gușă) pentru transformări biochimice sub acțiunea invertazei din secrețiile albinelor, pesticidele ajung în celulele de miere. Mierea, fiind alături de păstură, principala hrană pentru puiet și albinele tinere, poate provoca contaminarea organismului acestora. De asemenea, din florile melifere, prin intermediul polenului, pesticidele ajung în păstură, care reprezintă hrana proteică a tuturor castelor din familia de albine, în special, pentru puietul de albine lucrătoare și trântori. Prin urmare, păstura poate servi drept sursă de contaminare a organismului albinelor încă din fazele timpurii de dezvoltare a puietului. Mai mult ca atât, din corpul albinelor, prin intermediul secretului glandelor cerifere, pesticidele sunt difuzate în ceară, din care se construiesc celule de albine lucrătoare, de trântori și, foarte important, de regine. Din pereții ceriferi ai celulelor de faguri, larvele apicole pot fi contaminate cu pesticide la o vârstă destul de fragedă.

Datorită interacțiunilor biologice ale nectarului și polenului cu celulele fagurilor, puietul din cuib și produsele apicole, monitoringul pesticidelor din corpul albinelor poate fi folosit la evaluarea conformității mediului ambiant, în special, al florilor melifere, pentru conversia apiculturii convenționale în cea ecologică.

În acest context, scopul lucrării a fost cercetarea reziduurilor de pesticide în corpul albinelor și identificarea celor mai periculoase pesticide care pot afecta albinele melifere în condițiile sitului silvic.

\section{MATERIAL ȘI METODE}

Cercetările științifice au fost desfășurate asupra conținutului de reziduuri ale pesticidelor în probele de albine prelevate în luna iunie anul 
2018 din 5 familii ale stupinei experimentale a Institutului de Zoologie, amplasate la staționar în Ocolul silvic Ghidighici, Cantonul nr. 8, situat la 25 km nord-vest de mun. Chișinău. Fiecare probă cu albine a fost prelevată într-o pungă de plastic în cantitate de cca $100 \mathrm{~g}$ de albine lucrătoare. Probele cu albine, închise ermetic, au fost întroduse în congelator și menținute timp de 4 ore la temperatura de $-20^{\circ} \mathrm{C}$. Probele cu albine au fost prelevate, congelate și transportate la laborator, în conformitate cu Normele sanitar-veterinare privind metodologia de prelevare, prelucrare, ambalare și transport al probelor destinate examenelor de laborator [13].

Probele de albine au fost analizate la conținutul de reziduuri ale celor mai răspândite 11 pesticide, inclusiv: 1 insecticid organofosforic (Clorpirifos), 3 insecticide piretroide (Cipermetrin, Deltametrin, Tau-fluvalinat), 1 insecticid organoclorurat (Fipronil), 3 insecticide neonicotinoide (Clothianidin, Imidacloprid, Tiametoxam), 2 fungicide triazolice (Fenhexamid, Mepanipirim) și 1 acaricid (Amitraza).

Reziduurile de pesticide în probele de albine au fost determinate în Laboratorul acreditat pentru determinarea reziduurilor de pesticide al Întreprinderii de Stat "Centrul Național de Verificare și Certificare a Producției Vegetale și Solului", prin metodele GazCromatografiei - MasSpectrometrice (GC-MS) și LichidCromatografiei - MasSpectrometrice (LC-MS), descrise de Lazări I. (2000) în Culegerile de metode standarde SM [12].

Datele obținute, privind conținutul reziduurilor de pesticide în probele de albine, au fost comparate cu normele limitelor maxime admisibile (LMA), conform Regulamentului sanitar privind limitele maxime admise de reziduuri ale produselor de uz fitosanitar din/sau de pe produse alimentare și hrană de origine vegetală și animală pentru animale, aprobat prin Hotărârea Guvernului Republicii Moldova nr. 1191 din 23.12.2010 [15], ajustat la normele UE.

Datele obţinute în rezultatul comparărilor a două variabile și diferențele acestora au fost prelucrate statistic cu ajutorul softului computerizat "STATISTICA - 12" și apreciată certitudinea lor, conform statistcii biometrice variaţionale, după metodele lui П^охинский Н.A., 1989 [19]. 


\section{REZULTATE ȘI DISCUȚII}

Rezultatele analizelor de laborator ale probelor de albine, prelevate din stupina amplasată în Ocolul silvic (Cantonul nr. 8), au demonstrat că, la majoritatea pesticidelor cercetate ( 8 , sau $72,7 \%$ din cele 11 cercetate) nu au fost înregistrate valori detectabile de conținut al reziduurilor de pesticide (Tab.1).

Aceasta a fost și de așteptat, deoarece, potrivit unor cercetări anterioare ale noastre [2], efectuate într-un alt sit silvic (Cantonul nr. 9), în florile salcâmului alb (Robinia pseudoacacia) și teiului cu frunza lată (Tilia platyphillos), la $25 \%$ de pesticide din cele 17 cercetate, nu au fost înregistrate valori detectabile de reziduuri, iar la celelalte pesticide, au fost înregistrate concentrații foarte mici de reziduuri, inclusiv: la 3 insecticide piretroide (Cipermetrin, Deltametrin, Piretrin), 1 insecticid neonicotinoid (Clotianidin), 1 insecticid organofosforic (Fenamifos), 4 fungicide triazolice (Difenoconazol, Fenhexamid, Mepanipirim, Ciprodinil), 4 erbicide (Amidosulfuron, Amitrol, Glifosat, Sulfosulfurol) și 1 acaricid (Fipronil).

Însă, toate aceste concentrații de reziduuri ale pesticidelor nominalizate detectate în florile arborilor de pădure (salcâm și tei) au fost cu mult (de 1,3 - 33,3 ori) mai joase, decât nivelul limitelor maxime admisibile, conform normelor naționale și UE. În baza acestor rezultate, au fost făcute concluzii că, reziduurile de pesticide înregistrate de noi în florile arborilor silvici, nu prezintă careva pericol pentru sănătatea albinelor și fauna ecosistemei cercetate.

Tabelul 1. Conținutul reziduurilor de pesticide în corpul albinelor $(N=5), m g / k g$

\begin{tabular}{|l|l|l|l|l|}
\hline Denumirea pesticidului & LMA* & $M \pm m$ & $\begin{array}{l}\text { d } \\
\text { (M-LMA) }\end{array}$ & $\begin{array}{l}\text { M } \\
\text { față de LMA }\end{array}$ \\
\hline Insecticide organofosforice & 0,07 & nd & - & - \\
\hline Clorpirifos & \multicolumn{5}{l|}{} \\
\hline Insecticide piretroide & 0,02 & nd & - & - \\
\hline Cipermetrin & 0,01 & nd & - & - \\
\hline Deltametrin & 0,2 & $0,0062 \pm 0,0007$ & $-0,1938$ & $-32,2$ ori \\
\hline Tau-fluvalinat &
\end{tabular}




\begin{tabular}{|l|l|l|l|l|}
\hline Insecticide organoclorurate & 0,004 & nd & - & \multicolumn{1}{l|}{} \\
\hline Fipronil & \multicolumn{5}{l|}{} \\
\hline Insecticide neonicotinoide & 0,04 & nd & - & - \\
\hline Clothianidin & 0,08 & $0,0060 \pm 0,0006$ & $-0,074$ & $-13,3$ ori \\
\hline Imidacloprid & 0,02 & nd & - & - \\
\hline Tiametoxam & 0,1 & nd & - & - \\
\hline Fungicide triazolice & 0,02 & nd & - & - \\
\hline Fenhexamid & \multicolumn{5}{l}{} \\
\hline Mepanipirim & 0,01 & $0,0058 \pm 0,0006$ & $-0,0042$ & $-1,7$ ori \\
\hline Acaricide
\end{tabular}

Notificări: * - LMA, conform „Regulamentului sanitar privind limitele maxime admise de reziduuri ale produselor de uz fitosanitar din/sau de pe produse alimentare și hrană de origine vegetală și animală pentru animale, aprobat prin Hotărârea Guvernului RM nr. 1191 din 23.12.2010. www//lex.justice. md, vizitat la 06.08.2018.

Presupunem că, reziduurile de pesticide, migrând prin lanțul trofic din florile melifere până în corpul albinelor, cu timpul, în mare parte se descompun, iar concentrațiile acestora se diminuează substanțial și devin nedetectabile. Prin aceasta se explică faptul că, în corpul albinelor, sunt detectate tot mai puține pesticide decât în florile melifere ale aceluiaș sit în care sunt amplasate familiile de albine.

În cazul prezentei cercetări, în una din probele cu albine analizate au fost îdentificate concentrații detectabile de reziduuri ale 3 pesticide (insecticidului piretroid Tau-fluvalinat, insecticidului neonicotinoid Imidacloprid și acaricidului Amitraza), în o altă probă au fost înregistrate valori detectabile de reziduuri ale 2 pesticide (insecticidului neonicotinoid Imidacloprid și acaricidului Amitraza), în alte două probe au fost înregistrate valori detectabile de reziduuri ale 1 singur pesticid (insecticidului piretroid Tau-fluvalinat), iar în una din probe nu au fost înregistrate valori detectabile de reziduuri nici a unuia din pesticidele cercetate. Cel mai răspândit pesticid în probele de albine a fost insecticidul piretroid Tau-fluvalinat, reziduurile căruia au fost înregistrate în concentrații detectabile în 3 din cele 5 probe analizate. După acesta urmează insecticidul neonicotinoid Imidacloprid și acaricidul Amitraza, reziduurile cărora au fost înregistrate în concentrații 
detectabile în 2 probe din cele analizate. Putem afirma că, în cazul în care aceste pesticide vor fi întâlnite în concentrații mai mari de LMA pot fi considerate și cele mai periculoase.

Ținem să menționăm că, în prezenta cercetare, valorile concentrațiilor detectabile ale reziduurilor acestor pesticide au fost foarte mici. În medie, concentrația reziduurilor acaricidului Amitraza a fost de 0,0058 $\pm 0,0006$ $\mathrm{mg} / \mathrm{kg}$, a insecticidului neonicotinoid Imidacloprid - 0,0060 $\pm 0,0006 \mathrm{mg} /$ $\mathrm{kg}$ și a insecticidului piretroid Tau-fluvalinat - 0,0062 $\pm 0,0007 \mathrm{mg} / \mathrm{kg}$. Aceste concentrații de reziduuri ale pesticidelor detectate sunt, respectiv, de 1,$7 ; 13,3$ și 32,2 ori mai mici, comparativ cu limitele maxim admisibile, conform normelor naționale și UE. În baza acestor rezultate putem afirma că, mediul ambiant în care activează albinele melifere din familiile amplasate în situl silvic nu este poluat cu reziduuri de pesticide și, deci, nu reprezintă careva pericol pentru sănătatea albinelor, precum și pentru securitatea produselor apicole alimentare destinate consumului uman.

Totodată, în literatura de profil există informații că, unele pesticide, chiar și în doze mici, provoacă la insecte efecte devastatoare. Astfel, potrivit relatării lui Whitehorn P.R. et al., 2012 [17], insecticidul neonicotinoid Imidacloprid provoacă diminuări considerabile asupra dezvoltării coloniilor de bondari și, mai ales asupra reginelor. Bondarii care consumă hrană contaminată cu Imidacloprid au o rată de creștere mai scăzută și, ca rezultat, coloniile acestora sunt mai mici (cu 8-12\%). Mai mult decât atât, acest lucru se exprimă printr-un declin extrem de disproporționat al numărului de regine: 1-2 regine în coloniile contaminate, comparațiv cu 14, câte au fost observate în coloniile fără pesticide.

Prin urmare, deși concentrațiile reziduurilor de pesticide detectate în cercetările noastre au fost foarte mici, monitoringul acestora în coloniile de albine, în special - în corpul albinelor, capătă o deosebită importanță în contextul conversiei apiculturii convenționale în cea organică.

\section{CONCLUZII}

1. În probele de albine, prelevate din familiile stupinei amplasate la staționar în Ocolul silvic, la majoritatea pesticidelor cercetate $(72,7 \%)$ nu au fost înregistrate valori detectabile de conținut al reziduurilor de pesticide.

2. În $20 \%$ din probele de albine analizate nu a fost înregistrate reziduuri nici a unuia din cele 11 pesticide cercetate, în 40\% din probele de albi- 
ne au fost înregistrate valori detectabile de reziduuri doar a unui singur pesticid (insecticidul piretroid Tau-fluvalinat), în alte 20\% din probe au fost înregistrate valori detectabile de reziduuri ale 2 pesticide (insecticidul neonicotinoid Imidacloprid și acaricidul Amitraza) și, în celelalte 20\% din probele de albine au fost înregistrate valori detectabile de reziduuri ale 3 pesticide (insecticidul piretroid Tau-fluvalinat, insecticidul neonicotinoid Imidacloprid și acaricidul Amitraza).

3. Valorile concentrațiilor detectabile ale reziduurilor de pesticide înregistrate în probele de albine prelevate din Ocolul silvic au fost foarte mici, constituind în medie: la insecticidul piretroid Tau-fluvalinat 0,0062 $\pm 0,0007$ $\mathrm{mg} / \mathrm{kg}$; la insecticidul neonicotinoid Imidacloprid 0,0060 $00,0006 \mathrm{mg} / \mathrm{kg}$ și, la acaricidul Amitraza 0,0058 $00,0006 \mathrm{mg} / \mathrm{kg}$. Aceste concentrații de reziduuri ale pesticidelor detectate sunt de 1,7 - 32,2 ori mai mici, comparativ cu limitele maxim admisibile, conform normelor naționale și UE.

4. Mediul ambiant din situl silvic nu este poluat cu reziduuri de pesticide, prin urmare, nu reprezintă careva pericol de contaminare a familiilor de albine, care ar putea periclita sănătatea albinelor, precum și securitatea produselor apicole destinate consumului uman.

Cercetările științifice au fost efectuate în cadrul proiectului fundamental instituțional 15.817.02.12F "Diversitatea, structura și funcţionarea complexelor faunistice naturale și antropizate în contextul fortificării strategiei securităţii naționale a Republicii Moldova", finanțat din bugetul de stat.

\section{BIBLIOGRAFIE}

1. Alaux C. et al. Interactions between Nosema microspores and a neonicotinoid weaken honeybees (Apis mellifera). Environmental Microbiology, 12: 2010, p. 774-782.

2. Cebotari Valentina, Buzu I., Postolachi Olga et al. Content of pesticide residues in the flowers of the acacia and linden trees from the Moldavian Codri area. In: International Conference "Agriculture for Life, Life for Agriculture" at the University of Agronomic Sciences and Veterinary Medicine of Bucharest. Scientific papers. Series D. Animal Science. Ed. "CERES" Publ. House. Vol. LXI, categoria ISI, Bucharest, 2018, p. 216-123. ISSN 2285-5750, ISSN Online 2393-2260.

3. David A. et al. (2016) Widespread contamination of wildflower and bee-collected pollen with complex mixtures of neonicotinoids and fungicides commonly applied to crops. Environment International, 88, p. 169-178.

4. Declinul albinelor. Raport tehnic al laboratoarelor de cercetare Green-Peace. 2013. 48 p. http://www.greenpeace.org. (vizitat 17.10.2014). 
5. Garry Codling et al. Concentrations of neonicotinoid insecticides in honey, pollen and honey bees (Apis mellifera L.) in central Saskatchewan, Canada. In: Chemosphere 144 (2016), p. 2321- 2328.

6. Goulson, D. (2013) An overview of the environmental risks posed by neonicotinoid insecticides. Journal of Applied Ecology, 50, p. 977-987.

7. http://www.beyondpesticides.org/programs/ bee-protective- pollinators-andpesticides/ chemicals-implicated (vizitat la 22.06.2016).

8. http//www.maslina.slobodnadalmacija.hr/novosti/ID/19528/Glifosat, vizitat la 14.11.2017.

9. http//www.dubrovniknet.hr/novost.php?id=24696, vizitat la 14.11.2017.

10. https://www.pestcontrol- expert.ro/ blog/insecticide-fipronil- substanta-activa, vizitată la 13.08.2018.

11. Iwasa, T., Motoyama, N., Ambrose, J.T. and Roe, R.M. (2004) Mechanism for the differential toxicity of neonicotinoid insecticides in the honey bee, Apis mellifera. Crop Protection, 23, p. 371-378

12. Lazări I. și al. „Metode de determinare a reziduurilor pesticidelor în produsele alimentare, furajere și mediul înconjurător", Chișinău, 2000, vol. I, 496 p. și vol II, 416 p.

13. Normă sanitar-veterinară privind prelevarea probelor oficiale de la animalele vii și din produsele de origine animală, aprobată prin Hotărârea Guvernului Republicii Moldova nr 782 din 01.09.2010.

14. Oliveira RA, et al. Side-effects of thiamethoxam on the brain and midgut of the africanized honeybee Apis mellifera (Hymenopptera: Apidae). Environmental Toxicology, in press. 2013.

15. Regulament sanitar privind limitele maxime admise de reziduuri ale produselor de uz fitosanitar din sau de pe produse alimentare și hrană de origine vegetală și animală pentru animale, aprobat prin Hotărârea Guvernului Republicii Moldova nr. 1191 din 23.12.2010.

16. Thompson, H.M., Fryday, S.L., Harkin, S. and Milner, S. (2014) Potential impacts of synergism in honeybees (Apis mellifera) of exposure to neonicotinoids and sprayed fungicides in crops. Apidologie, 45, p. 545-553

17. Whitehorn, P.R., O'Connor, S., Wackers, F.L. and Goulson, D. (2012) Neonicotinoid pesticide reduces bumble bee colony growth and queen production. Science, 336, p. 351-352

18. Королев А.В. Гибель пчелиных семей в 2014 году. «Пчеловодство», №3, Москва, 2015, с. 3-5. ISSN-0369-8629.

19. Плохинский Н.А. РуковоАство по биометрии Аля зоотехников. ИзА. «Колос», Москва, 1989, 256 с. 